\author{
Vietnam Journal of Mechanics, VAST, Vol.39, No.3 (2017), pp. 191-202 \\ DOI:10.15625/0866-7136/8334
}

\title{
RESERVOIRS OPTIMIZATION WITH DYNAMIC PROGRAMMING
}

\author{
Phan Thi Thu Phuong ${ }^{1, *}$, Dao Thi Ngoc Han ${ }^{1}$, Hoang Van Lai ${ }^{2}$, Bui Dinh Tri ${ }^{2}$ \\ ${ }^{1}$ Hanoi University of Civil Engineering, Vietnam \\ ${ }^{2}$ Institute of Mechanics, Vietnam Academy of Science and Technology, Hanoi, Vietnam \\ *E-mail: phuongimech@yahoo.com
}

Received May 15, 2016

\begin{abstract}
Differential Evolution (DE) and Dynamic Programming (DP) are important optimal methods in reservoir regulation. In the previous work [1], we presented the outline of DE, and applied it into Pleikrong reservoir, a big one in the Highland of Vietnam for dry season of 2010 year. Continuing from that, in this work, we present the outline of DP and then again, apply it to Pleikrong reservoir; and also apply it to Ialy, the biggest reservoir in Sesan cascade in the Highland of Vietnam; to reach optimal regulation for the maximum power production in the dry season of two years: 2010 and 2012. The results getting from DP are compared to the results by using DE. The results by these two methods have the same trend of releases which is storing the water at the beginning and significantly releasing at the end of the calculation time.
\end{abstract}

Keywords: Dynamic programming, reservoirs, cascade, Sesan, optimization.

\section{INTRODUCTION}

Many problems in economics, mathematics, engineering, agriculture, and so on, require optimal solution. Therefore, the methods to reach the optimal solution have been researched for a long time and been enhanced, expanded and combined, modified and developed over time with the development of computer science and the greater and greater need of practical calculation. Optimization methods are different analyses to get the best target under a set of constraints. Optimization problems have many categories: linear or nonlinear, deterministic or stochastic, static or dynamic, continuous or discrete, single or multi objective $[2,3]$. This classification is based on the character of both objective functions and the constraints. Many methods are studied to solve these problems such as Linear Programming (LP), Dynamic Programming (DP), Nonlinear Programming (NLP), Genetic Algorithm (GA), etc [4-6]. These methods are also being improved and developed into many versions to adapt to specific problems with specific characteristics separately [7-10].

(C) 2017 Vietnam Academy of Science and Technology 
Dynamic Programming (DP) is a recent, large-scale-applied optimization method which is researched and used worldwide. In Vietnam, this method is used more frequently in many researches. In 2003, Ha Van Khoi shown that DP could be applied to plan and regulate a power plant cascade [11]. That research tested DP to 3 reservoirs of Da river and claimed that DP had overcome the local optimal than other linear methods, however, the amount of calculation is big and the test cases are made with many suggestions of the inflow. In 2012, Le Hung set the optimal reservoir problem and used DP to apply for some reservoirs to show that this method is a good tool for planning water resource [12].

In Vietnam, to operate and regulate reservoirs, many ministries get involved such as the Ministry of Industry and Trade, Ministry of Agriculture and Rural Development, Ministry of Natural Resources and Environment, etc. The reservoir operation must not only be reasonable, consistent with agricultural seasons, time of electricity using peak, but also need reasonably discharged to avoid flood in rainy season, and to store enough water in dry season. Therefore, reservoir optimization problem is a significant practice problem in the world and Vietnam in particular. Even in a specific river cascade, regulation of a reservoir to get maximum electricity production objective only is not easy because the optimal standards are various, only applicable to each separate project, and not general.

\section{PROCESS OF OPTIMIZATION BY DYNAMIC PROGRAMMING}

\subsection{Outline of Dynamic Programming}

The concept called Dynamic Programming was first introduced by Bellman in 1957 [13]. Since then, Dynamic Programming (DP) has become a major research sector in applied mathematics, basic researches and computer science. It has also become an optimization method that has been widely using in many fields such as technology, economy, planning and management, etc [14-17].

Bellman used the concept "Dynamic Programming" to describe the process of solving problems to find the best one in a group of decisions. "Programming" means using different methods to get the optimal solution, and "dynamic" mentions the aspect of time in the problem. The optimality principle of Bellman about the optimization problem in recursive form is the core of DP:

"An optimal policy has the property that whatever the initial state and initial decisions are, the remaining decisions must constitute an optimal policy with regard to the state resulting from the first decisions" [13].

The process of an optimization can be described as [18] (Fig. 1), where $S_{t}$ : states variables, depended on controls and inputs, $r_{t}$ : control variables, selected to maximize or minimize the benefit, $I_{t}$ : input variables, $r_{t}\left(S_{t}\right)$ : decision rule, is the

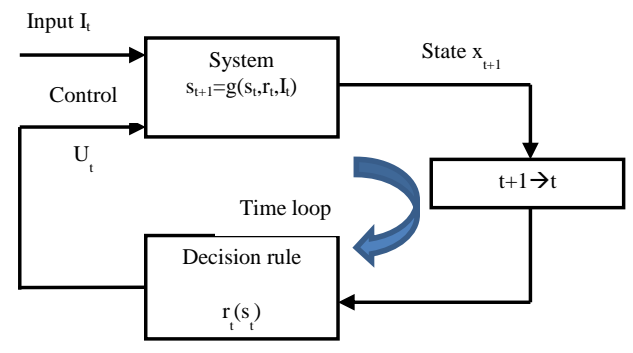

Fig. 1. Process of optimization function that gives $u_{t}$ for any $x_{t}, S_{t+1}=g\left(S_{t}, r_{t}, I_{t}\right)$ : state equation, $S_{0}$ : initial condition. 
This method is usually applied to problems that are sequential. The simple idea of this method is: instead of solving a complicated problem, we solve each separated part of it then combine the result of each part into an overall result. Each small part of the problem only done once by DP and thus the number of calculations is reduced [12].

In other words, DP discomposes an $\mathrm{N}$-decision problem into $\mathrm{N}$ of separate, interrelated sub-problems, each sub-problem is a stage. Each stage is characterized by chosen state variables. The decision analysis from this stage to the next one until reaching the last one could be done through space or time by control the decision variables.

The frame work of DP could be described as below [18] (Fig. 2).

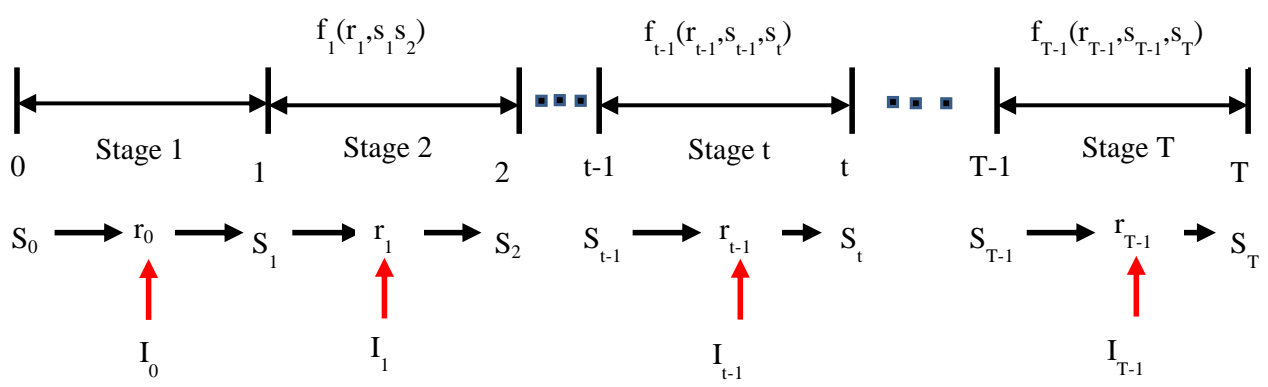

Fig. 2. Frame work of DP

The optimization problem is selecting $r_{0}, \ldots, r_{T-1}$ to maximize the benefit. The benefit of the problem could be described in the recursive equation as below [16]

$$
F_{j}^{*}\left(S_{j}\right)=\max _{R_{j}}\left\{E_{j}\left(S_{j}, r_{j}\right)+F_{j+1}^{*}\left(S_{j+1}\right)\right\},
$$

where $j$ : current stage, $F_{j+1}^{*}$ : accumulated sub-optimal benefits for future stages $j+1, j+$ $2, \ldots, T$, could be the power production in reservoir optimal problem, $T$ : total number of stages, $S_{j}$ : system state at stage $j$, is the water level or storage in reservoir optimal problem, $S_{j+1}=g\left(S_{j}, r_{j}, t\right)$ : state transformation equation, $r_{j}$ : decision taken at stage $j$, is the release in reservoir optimal problem, $E_{j}\left(S_{j}, r_{j}\right)$ : benefit or contribution of the decision $r_{j}$ given state $S_{j}$ at the initial stage, could be energy or power production at state $j$ in reservoir optimal problem.

In the reservoir optimization problem, states variables could be water levels or the corresponding reservoir volumes; the control variables could be the releases, and the objective function could be the hydro power production. In this case, the chart and the flow diagram of the optimal trajectory as Figs. 3 and 4 below [16], which could be shortly explained as:

We separate the storage volume of the reservoir into $n$ parts which is called $n$ states of the reservoir.

We separate the calculating time, in this case is 130 days, into 14 parts, then call them 14 stages. Each stage is 10 days.

The volume of the reservoir at the starting time is $V_{0}$ at stage 0 . 
From volume $V_{0}$ at stage 0 , there are many ways to go to stage 1 by many ways of release water. With each way of release, we can calculate the corresponding electricity. The release give the highest electricity from stage 0 to stage 1 is the optimal solution for the first step.

Repeat the same sequence with other steps to reach the optimal releases to get optimal electricity production.

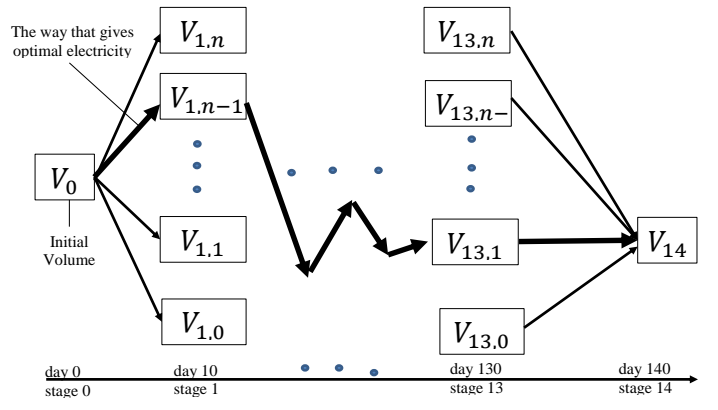

Fig. 3. Chart of the optimal trajectory in forward computational procedure

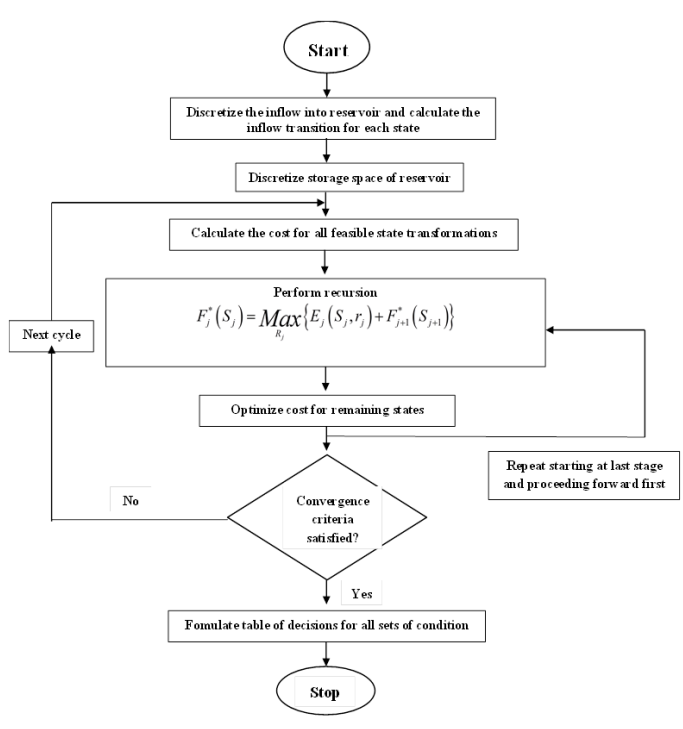

Fig. 4. Flow diagram for the DP model of a reservoir [16]

\subsection{Application of dynamic programming}

We now apply DP to maximize the total electricity production over a prespecified time period of two biggest reservoirs of Sesan cascade: Pleikrong and Ialy.

In this work, we apply DP to find the optimal set of releases to get the maximum power production of each reservoir in the years of 2010 and 2012.

The objective function in this case is:

$$
E=\operatorname{maximum} \sum E_{j}(j=1, \ldots, T),
$$

where

$E_{i}=9.8 * h_{i} * Q_{i} * k * 24 * 10 / 1000(\mathrm{MWh})$,

$h_{i}$ - water height at time period $i$,

$Q_{i}$ - release at time period $i$,

$k$ - overall generation efficiency.

The problem is created as in [1] which means calculation time is in dry season of Sesan cascade. It starts at the beginning of December and ends in the next June. The reservoir management is followed the operation rules in the decision No. 1182 QD-TTg of the Government of Vietnam signed in July 17, 2014 [19]. 
The data that is used in this paper was provided by the team of Institute of Mechanics of VAST in project of building the reservoir operation for Sesan cascade in dry season (under contract N 01/2011/QTVH - SESAN on June 02, 2011).

The results by DP of Pleikrong and Ialy reservoirs are shown as the charts and Tables below. These results are compared to the results by Differential Evolution which is a method in Genetic group that we presented in our previous work [1].

\subsubsection{Application to Pleikrong reservoir}

Pleikrong hydropower plant is located at the upstream of Sesan river in the Highland of Vietnam. It has a significant affect to the other plants of this cascade. The main objectives of Pleikrong reservoir are storing water for the whole Sesan cascade and producing electricity to regulate flooding in rainy season and enhance the capacity of the lower plants, see Fig. 5.

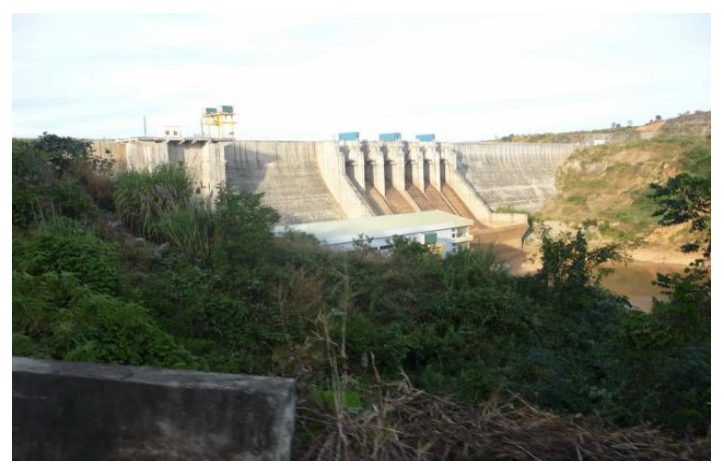

Fig. 5. Pleikrong damp

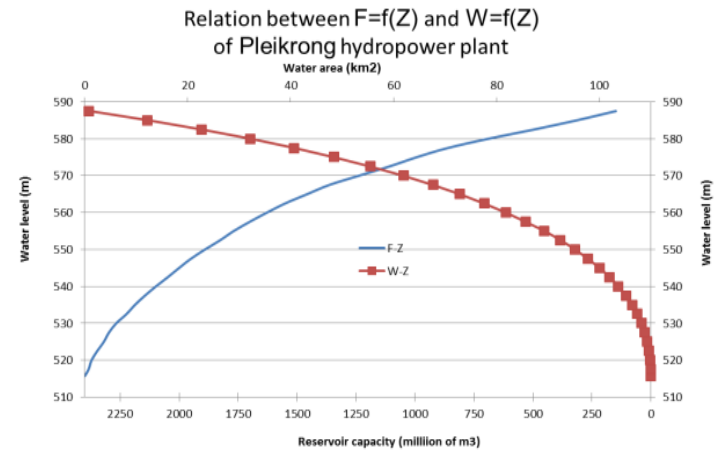

Fig. 6. Relationship between water levels $Z$ and storage volumes $W$ of the Pleikrong reservoir

Water height is non-linearly related to the volume of the reservoir. To calculate the objective function, we need to have the corresponding water heights of the volumes. The relationship between water levels and the volumes is given in the operation rules in the decision No. 1182 QD-TTg of the Government of Vietnam signed on July 17, 2014 [19] in Fig. 6.

There are some constraints that the calculating must be satisfied, such as the storage volume of the reservoir must be lower the given useful volume, the releases must be lower than the designed maximum release. We also need some other data such as the inflows to the reservoir, the initial water level is given by the initial volume. These inputs of the problem are shown in Tabs. 1 and 2.

Table 1. Other input of Pleikrong reservoir in the year 2010 and 2012

\begin{tabular}{|c|c|c|c|}
\hline & $\begin{array}{c}\text { Useful capacity } \\
W\left(\times 10^{3} \mathrm{~m}^{3}\right)\end{array}$ & $\begin{array}{c}\text { Initial water } \\
\text { level } Z(\mathrm{~m})\end{array}$ & $\begin{array}{c}\text { Maximum of average } \\
\text { release } Q_{i}\left(\mathrm{~m}^{3} / \mathrm{s}\right)\end{array}$ \\
\hline 2010 & 948.43 & 569.0 & 330 \\
\hline 2012 & 948.43 & 569.06 & 330 \\
\hline
\end{tabular}


Table 2. Inflow of Pleikrong reservoir in the year 2010 and 2012

\begin{tabular}{|c|c|c|c|}
\hline $\begin{array}{c}\text { No } \\
\text { period }\end{array}$ & $\begin{array}{c}\text { Time of } \\
\text { period }\end{array}$ & $\begin{array}{c}\text { Inflow of Pleikrong } \\
\text { reservoir }\left(\mathrm{m}^{3} / \mathrm{s}\right) \text { in 2010 }\end{array}$ & $\begin{array}{c}\text { Inflow of Pleikrong } \\
\text { reservoir }\left(\mathrm{m}^{3} / \mathrm{s}\right) \text { in 2012 }\end{array}$ \\
\hline 1 & 11/Feb - 20/Feb & 47.73 & 48.7 \\
\hline 2 & 21/Feb - 02/Mar & 53.35 & 52.2 \\
\hline 3 & 03/Mar - 12/Mar & 23.79 & 51.5 \\
\hline 4 & 13/Mar-22/Mar & 51.8 & 31.6 \\
\hline 5 & 23/Mar - 01/Apr & 31.98 & 24.5 \\
\hline 6 & 02/Apr - 11/Apr & 10.86 & 46.1 \\
\hline 7 & 12/Apr - 21/Apr & 44.56 & 37.8 \\
\hline 8 & 22/Apr - 01/May & 41.18 & 45.3 \\
\hline 9 & 02/May - 11/May & 14.54 & 37.3 \\
\hline 10 & 12/May - 21/May & 23.54 & 45.6 \\
\hline 11 & 22/May - 31/May & 0.09 & 62.2 \\
\hline 12 & 01/Jun - 10/Jun & 17.15 & 131.6 \\
\hline 13 & 11/Jun - 20/Jun & 44.76 & 235.6 \\
\hline 14 & 21/Jun - 30/Jun & 36.48 & \\
\hline
\end{tabular}

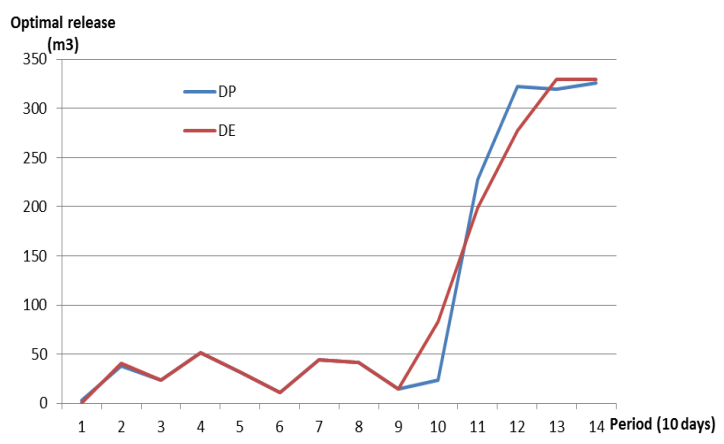

Fig. 7. Results for Pleikrong reservoir in 2010 by DP and DE

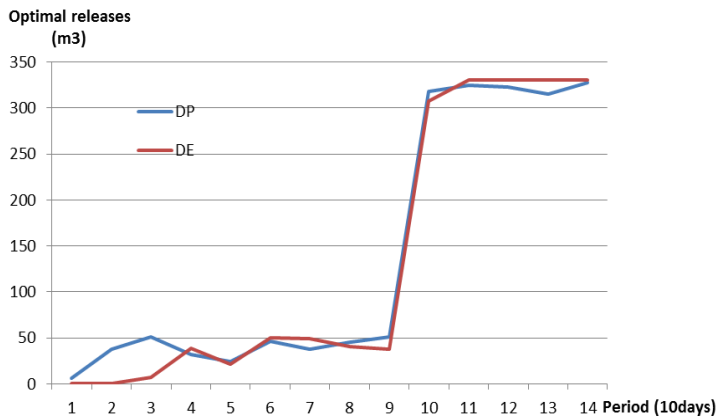

Fig. 8. Results for Pleikrong reservoir in 2012 by DP and DE

In Fig. 7, the releases from the first period to the $9^{\text {th }}$ period are equal to the inflows. This means that at the beginning of the dry season, water is stored to reach to the maximum water level. Then releases are higher and higher at the end of the season. This way of release could give the highest power production. The releases are also given in the table form in Tab. 3.

The results of Pleikrong reservoir in 2012 are shown in Fig. 8. In Fig. 8, water is also stored at the beginning periods and highly released at the ending periods. The detail optimal releases are also shown in table form as in Tab. 4. 
Table 3. Optimal releases of Pleikrong reservoir by DP and DE in 2010

\begin{tabular}{|c|c|c|c|}
\hline $\begin{array}{c}\text { No } \\
\text { period }\end{array}$ & $\begin{array}{l}\text { Time of } \\
\text { period }\end{array}$ & $\begin{array}{c}\text { Optimal releases } \\
\text { of Pleikrong reservoir } \\
\text { by DP }\left(\mathrm{m}^{3} / \mathrm{s}\right)\end{array}$ & $\begin{array}{c}\text { Optimal releases } \\
\text { of Pleikrong reservoir } \\
\text { by DE }\left(\mathrm{m}^{3} / \mathrm{s}\right)\end{array}$ \\
\hline 1 & $11 /$ Feb - 20/Feb & 2.540329861 & 0.0 \\
\hline 2 & 21/Feb - 02/Mar & 38.28677662 & 40.53416590 \\
\hline 3 & 03/Mar - 12/Mar & 23.79 & 23.78999995 \\
\hline 4 & 13/Mar - 22/Mar & 51.8 & 51.80000037 \\
\hline 5 & 23/Mar - 01/Apr & 31.98 & 31.98000024 \\
\hline 6 & 02/Apr - 11/Apr & 10.86 & 10.86000043 \\
\hline 7 & 12/Apr - 21/Apr & 44.56 & 44.56000130 \\
\hline 8 & 22/Apr - 01/May & 41.18 & 41.17999976 \\
\hline 9 & 02/May - 11/May & 14.54 & 14.53999904 \\
\hline 10 & 12/May - 21/May & 23.54 & 83.22103829 \\
\hline 11 & 22/May - 31/May & 228.1684399 & 199.33007812 \\
\hline 12 & 01/Jun - 10/Jun & 322.287357 & 277.37941453 \\
\hline 13 & 11/Jun - 20/Jun & 319.3836213 & 329.80134326 \\
\hline \multirow[t]{3}{*}{14} & 21/Jun - 30/Jun & 326.3604892 & 329.97833269 \\
\hline & Electrical production & $141060.59331938 \mathrm{MWh}$ & $141079.0869 \mathrm{MWh}$ \\
\hline & Real electrical production & $133547 \mathrm{MWh}$ & \\
\hline
\end{tabular}

Table 4. Optimal releases of Pleikrong by DP and DE in 2012

\begin{tabular}{|c|c|c|c|}
\hline $\begin{array}{c}\text { N0 } \\
\text { period }\end{array}$ & Time of period & $\begin{array}{c}\text { Optimal releases of } \\
\text { Pleikrong reservoir } \\
\text { by DP }(\mathrm{m3} / \mathrm{s})\end{array}$ & $\begin{array}{c}\text { Optimal releases of } \\
\text { Pleikrong reservoir } \\
\text { by DE (m3/s) }\end{array}$ \\
\hline 1 & 11/Feb - 20/Feb & 6.164844 & 0 \\
\hline 2 & 21/Feb - 02/Mar & 38.02161 & 0 \\
\hline 3 & 03/Mar - 12/Mar & 51.5 & 7.474769 \\
\hline 4 & 13/Mar - 22/Mar & 31.6 & 38.9 \\
\hline 5 & 23/Mar - 01/Apr & 24.5 & 21.69 \\
\hline 6 & 02/Apr - 11/Apr & 46.1 & 40.01 \\
\hline 7 & 12/Apr - 21/Apr & 37.8 & 49.51 \\
\hline 8 & 22/Apr - 01/May & 45.3 & 37.58 \\
\hline 9 & 02/May - 11/May & 51.47839 & 307.9099 \\
\hline 10 & 12/May - 21/May & 317.7689 & 330 \\
\hline 11 & 22/May - 31/May & 324.4605 & 330 \\
\hline 12 & 01/Jun - 10/Jun & 322.4516 & 330 \\
\hline 13 & 11/Jun - 20/Jun & 315.307 & \\
\hline 14 & 21/Jun - 30/Jun & 327.4535 & $\mathbf{1 6 9} \mathbf{1 0 6 . 5 1 6 6 ~} \mathbf{M W h}$ \\
\hline & Electrical production & $\mathbf{1 7 4} \mathbf{1 8 3 . 5 6 4 3 6 0 5 7} \mathbf{M W h}$ & \\
\hline & Real electrical production & $\mathbf{1 3 4} \mathbf{0 5 8 . 3 5} \mathbf{M W h}$ & \\
\hline
\end{tabular}




\subsubsection{Application to Ialy reservoir}

Ialy hydropower plant is the biggest one in Sesan cascade and the second one in Vietnam, after Hoa Binh power plant, see Fig. 9. Pleikrong release and Dabla river are two inflows of Ialy reservoir. Ialy power plant supplies most of the energy for the Highland of Vietnam.

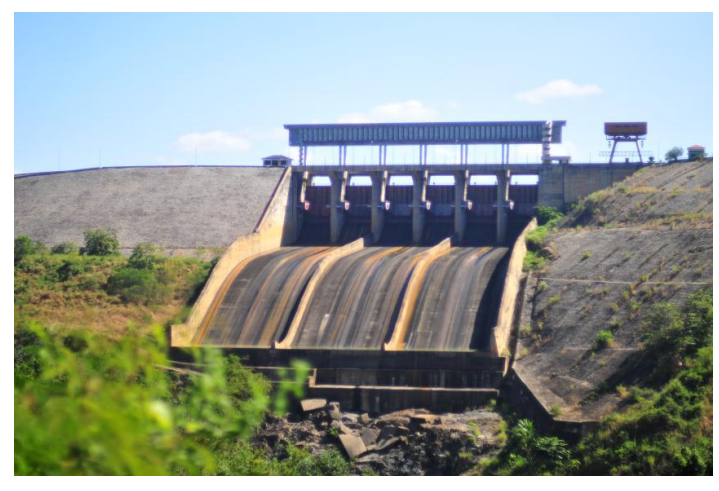

Fig. 9. Ialy damp

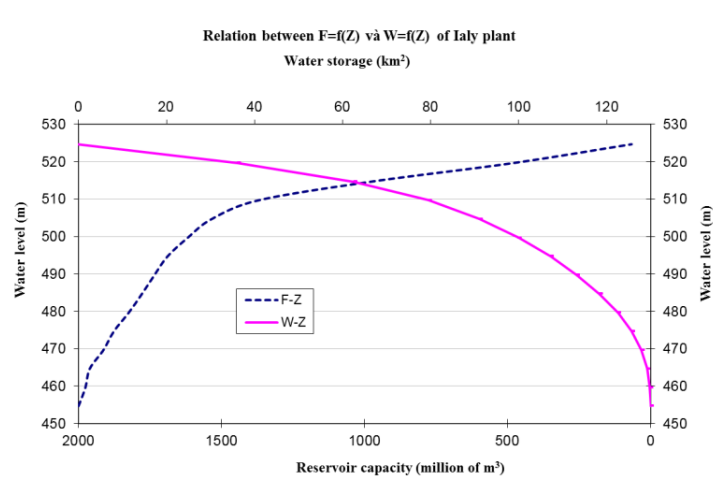

Fig. 10. Relationship between water levels $\mathrm{Z}$ and storage volumes $\mathrm{W}$ of the Ialy reservoir

The relationship between water levels and the volumes of Ialy reservoir is given [19], as Fig. 10. The constraints for Ialy reservoir and the initial data are given in Tab. 5 and Tab. 6.

Table 5. Other input of Ialy in the year 2010 and 2012

\begin{tabular}{|c|c|c|c|}
\hline & $\begin{array}{c}\text { Useful capacity } \\
\mathrm{W}\left(\times 10^{3} \mathrm{~m}^{3}\right)\end{array}$ & $\begin{array}{c}\text { Initial water level } \\
\mathrm{Z}(\mathrm{m})\end{array}$ & $\begin{array}{c}\text { Maximum of average release } \\
\mathrm{Q}_{i}\left(\mathrm{~m}^{3} / \mathrm{s}\right)\end{array}$ \\
\hline 2010 & 619,74 & 660,769548 & 420 \\
\hline 2012 & 619,74 & 987,967877 & 420 \\
\hline
\end{tabular}

The optimal releases of Ialy reservoir in 2010 are shown in Tab. 7 and Fig. 11. In this Fig. 11, we can see that water is firstly stored at the beginning periods to reach maximum water level. Then it starts to release because of the inflows are high. The releases from the $6^{\text {th }}$ period to $12^{\text {th }}$ period are up and down, depended on the inflows to keep the maximum water level. At the end of the season, water is released maximum for maximum power production.

The results calculating for Ialy reservoir in 2012 are shown as in Tab. 8 and Fig. 12. As shown in Tab. 8 and Fig. 12, water is released right at the beginning of the season. It is different to Tab. 7 and Fig. 10 for results in 2010. The reason is in 2012 water of Ialy reservoir is excess. Then water releases depend on the inflows to the reservoir. It needs to keep the maximum water level. Finally, the releases are increased at the end of the season to get maximum power production. 
Table 6. Inflow of Ialy in the year 2010 and 2012

\begin{tabular}{|c|c|c|c|}
\hline No period & Time of period & $\begin{array}{c}\text { Inflow of Ialy reservoir } \\
\text { in } 2010\left(\mathrm{~m}^{3} / \mathrm{s}\right)\end{array}$ & $\begin{array}{c}\text { Inflow of Ialy reservoir } \\
\text { in 2012 }\left(\mathrm{m}^{3} / \mathrm{s}\right)\end{array}$ \\
\hline 1 & 11/Feb - 20/Feb & 87.73 & 125.43 \\
\hline 2 & 21/Feb - 02/Mar & 119.4 & 130.5 \\
\hline 3 & 03/Mar - 12/Mar & 117.63 & 150.78 \\
\hline 4 & 13/Mar - 22/Mar & 126.35 & 167.21 \\
\hline 5 & 23/Mar - 01/Apr & 189.48 & 207.33 \\
\hline 6 & 02/Apr - 11/Apr & 248.25 & 146.28 \\
\hline 7 & 12/Apr - 21/Apr & 215.98 & 190.29 \\
\hline 8 & 22/Apr - 01/May & 169.2 & 170.35 \\
\hline 9 & 02/May - 11/May & 223.25 & 228.04 \\
\hline 10 & 12/May - 21/May & 188.08 & 235.81 \\
\hline 11 & 22/May - 31/May & 124.88 & 256.51 \\
\hline 12 & 01/Jun - 10/Jun & 109.95 & 267.05 \\
\hline 13 & 11/Jun - 20/Jun & 100.65 & 266.87 \\
\hline 14 & 21/Jun - 30/Jun & 81.13 & \\
\hline
\end{tabular}

Table 7. Optimal releases of Ialy reservoir by DP and DE in 2010

\begin{tabular}{|c|c|c|c|}
\hline No period & Time of period & $\begin{array}{c}\text { Optimal releases } \\
\text { of Ialy reservoir } \\
\text { by DP }\left(\mathrm{m}^{3} / \mathrm{s}\right)\end{array}$ & $\begin{array}{c}\text { Optimal releases } \\
\text { of Ialy reservoir } \\
\text { by } \mathrm{DE}\left(\mathrm{m}^{3} / \mathrm{s}\right)\end{array}$ \\
\hline 1 & 11/Feb - 20/Feb & 8.386377 & 0 \\
\hline 2 & 21/Feb - 02/Mar & 0.384566 & 0 \\
\hline 3 & 03/Mar - 12/Mar & 58.12228 & 72.479129904 \\
\hline 4 & 13/Mar - 22/Mar & 126.35 & 101.31 \\
\hline 5 & 23/Mar - 01/Apr & 189.48 & 188.70 \\
\hline 6 & 02/Apr - 11/Apr & 248.25 & 236.27 \\
\hline 7 & 12/Apr - 21/Apr & 215.98 & 223.31 \\
\hline 8 & 22/Apr - 01/May & 169.2 & 165.54 \\
\hline 9 & 02/May - 11/May & 223.25 & 238.79 \\
\hline 10 & 12/May - 21/May & 188.08 & 134.46 \\
\hline 11 & 22/May - 31/May & 124.88 & 118.99 \\
\hline 12 & 01/Jun - 10/Jun & 179.3757 & 163.57164806 \\
\hline 13 & 11/Jun - 20/Jun & 418.9286 & 420 \\
\hline \multirow[t]{3}{*}{14} & 21/Jun - 30/Jun & 410.7174 & 420 \\
\hline & Electrical production & $1107901.5565 \mathrm{MWh}$ & 1081234.9943 MWh \\
\hline & Real electrical production & $1063948 \mathrm{MWh}$ & \\
\hline
\end{tabular}




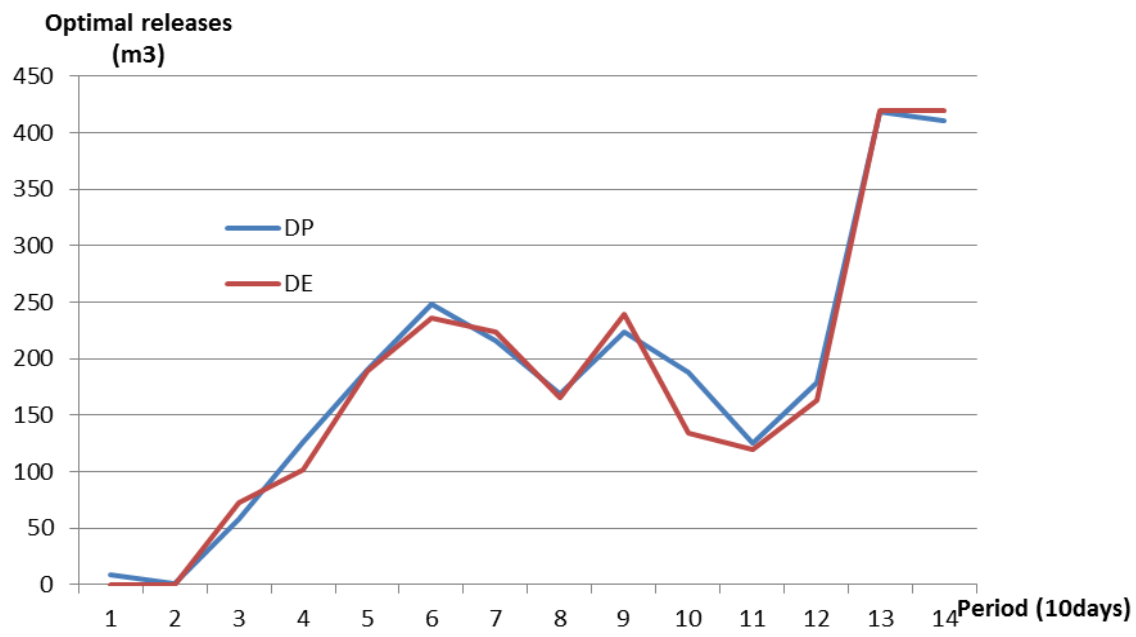

Fig. 11. Reults for Ialy reservoir by DP and DE in 2010

Table 8. Optimal releases of Ialy reservoir by DP and DE in 2012

\begin{tabular}{|c|c|c|c|}
\hline No period & Time of period & $\begin{array}{l}\text { Optimal releases } \\
\left(\mathrm{m}^{3} / \mathrm{s}\right) \text { by DP }\end{array}$ & $\begin{array}{l}\text { Optimal releases } \\
\left(\mathrm{m}^{3} / \mathrm{s}\right) \text { by DE }\end{array}$ \\
\hline 1 & 11/Feb - 20/Feb & 246.2649961 & 246.2609 \\
\hline 2 & 21/Feb - 02/Mar & 130.5 & 130.5 \\
\hline 3 & 03/Mar - 12/Mar & 150.78 & 150.78 \\
\hline 4 & 13/Mar - 22/Mar & 167.21 & 167.21 \\
\hline 5 & 23/Mar - 01/Apr & 207.33 & 207.33 \\
\hline 6 & 02/Apr - 11/Apr & 146.28 & 146.28 \\
\hline 7 & 12/Apr - 21/Apr & 190.29 & 190.29 \\
\hline 8 & 22/Apr - 01/May & 170.35 & 170.35 \\
\hline 9 & 02/May - 11/May & 190.68 & 190.68 \\
\hline 10 & 12/May - 21/May & 307.7390741 & 291.5716 \\
\hline 11 & 22/May - 31/May & 415.1329167 & 420 \\
\hline 12 & 01/Jun - 10/Jun & 415.9081481 & 420 \\
\hline 13 & 11/Jun - 20/Jun & 416.4857639 & 420 \\
\hline \multirow[t]{3}{*}{14} & 21/Jun - 30/Jun & 416.3057639 & 420 \\
\hline & Electrical production & $1486726.6824 \mathrm{MWh}$ & 1486 667.4 MWh \\
\hline & Real electrical production & $1392585 \mathrm{MWh}$ & \\
\hline
\end{tabular}




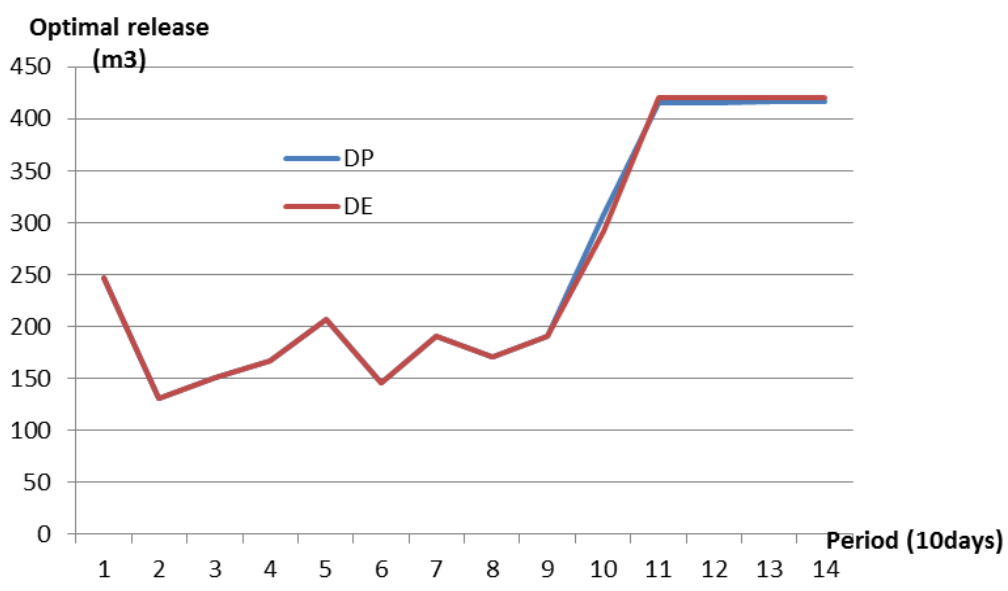

Fig. 12. Results for Ialy reservoir in 2012 by DP and DE

\section{CONCLUSION}

The electricity productions and the set of the releases getting by these two methods are close to each other, respectively. The slight differences between them depend on the input of the year, for example, in 2010, the water levels and the inflows are low, DE gives higher amount of electricity production; while in 2012, the water levels and the inflows are high, then DP gives a slightly higher production. However, electricity productions using both these two optimization methods are much higher than the real production. That could be concluded that DP and DE are reliable methods for reservoir optimization problems.

\section{REFERENCES}

[1] P. T. T. Phuong, H. V. Lai, and B. D. Tri. Reservoir optimization with differential evolution. Vietnam Journal of Mechanics, 38, (1), (2016), pp. 39-48. doi:10.15625/0866-7136/38/1/6490.

[2] V. Chandramouli and H. Raman. Multireservoir modeling with dynamic programming and neural networks. Journal of Water Resources Planning and Management, 127, (2), (2001), pp. 89 98. doi:10.1061/(asce)0733-9496(2001)127:2(89).

[3] N. L. C. Dias, M. V. F. Pereira, and J. Kelman. Optimization of flood control and power generation requirements in a multi-purpose reservoir. IFAC Proceedings Volumes, 18, (7), (1985), pp. 101-104. doi:10.1016/s1474-6670(17)60421-x.

[4] D. P. Loucks, E. Van Beek, J. R. Stedinger, J. P. M. Dijkman, and M. T. Villars. Water resources systems planning and management: an introduction to methods, models and applications. UNESCO, Hydraulics, (2005).

[5] K. D. W. Nandalal. Reservoir management under consideration of stratification and hydraulic phenomena. PhD thesis, Department of Water Resources, Wageningen Agricultural University, Netherlands, (1995).

[6] W. W.-G. Yeh. Reservoir management and operations models: A state-of-the-art review. Water Resources Research, 21, (12), (1985), pp. 1797-1818. doi:10.1029/WR021i012p01797.

[7] V. T. Chow. Methodology for water resources planning: DDDP and MLOM. Water Resourses Research, University of Illinois, (1971). 
[8] R. E. Larson. State increment dynamic programming. Elsevier, New York, (1968).

[9] S. E. Dreyfus and A. M. Law. Art and theory of dynamic programming. Academic Press, Inc., (1977).

[10] M. Heidari, V. T. Chow, P. V. Kokotović, and D. D. Meredith. Discrete differential dynamic programing approach to water resources systems optimization. Water Resources Research, 7, (2), (1971), pp. 273-282. doi:10.1029/wr007i002p00273.

[11] H. V. Khoi and L. B. Trung. Applying of 2-D dynamic programming to find the optimal hydropower reservoir system operation. Journal of Water resources and Environmental Engineering, 1, (2003), pp. 37-43. (in Vietnamese).

[12] L. Hung. Multi-objective reservoirs optimization. PhD thesis, Da Nang University, (2012).

[13] R. Bellman. Dynamic programming. Princeton University Press, (1957).

[14] J. W. Labadie. Generalized dynamic programming package: CSUDP - Documentation and user guide. Colorado State University, (2003).

[15] J. W. Labadie. Optimal operation of multireservoir systems: State-of-the-art review. Journal of Water Resources Planning and Management, 130, (2), (2004), pp. 93-111. doi:10.1061/(ASCE)0733-9496(2004)130:2(93).

[16] K. D. W. Nandalal and J. J. Bogardi. Dynamic programming based operation of reservoirs: Applicability and limits. Cambridge University Press, (2007). doi:10.1017/cbo9780511535710.

[17] P. Nopmongcol and A. J. Askew. Multilevel incremental dynamic programing. Water Resources Research, 12, (6), (1976), pp. 1291-1297. doi:10.1029/wr012i006p01291.

[18] Real-time optimization, dynamic programming. Technical report, Lecture 19- 20, 1.731 Water Resource Systems, Department of Civil and Environmental Engineering, Massachusetts Institute of Technology, (2006).

[19] Operation procedure of the inter-reservoir on Sesan river basin. No 1182/QD-TTg, (2014). (in Vietnamese). 